\title{
Impulsive Behavior
}

National Cancer Institute

\section{Source}

National Cancer Institute. Impulsive Behavior. NCI Thesaurus. Code C93213.

Initiation of actions without forethought as to the cost, results or consequences. 